\title{
Despertando para a cultura material: representações midiáticas do café e do chocolate na publicidade
}

Cláudia da Silva Pereira

\section{Resumo}

0 objetivo do artigo é discutir, à luz das teorias antropológicas, especialmente daquelas dedicadas à análise do consumo e da cultura material como fenômenos sociais, as representações de determinadas "coisas" em suas relações com valores e práticas da cultura ocidental contemporânea aqui, o café e o chocolate, em suas representações midiáticas na Publicidade. Para tanto, este trabalho sustenta-se em autores como Marshall Sahlins (2003) e Daniel Miller (1987), entre outros. A partir do que foi aqui analisado, reforçam-se as premissas de que "coisas" e "pessoas" constituem partes de uma mesma ontologia cultural, ligadas por lógicas que estão para além da razão prática.

\section{Palavras-Chave}

Cultura material. Representações midiáticas.

Publicidade.
Cláudia da Silva Pereira I caupereira@gmail.com Doutora em Antropologia pela Universidade Federal do Rio de Janeiro, UFRJ - Brasil. Professora do Programa de Pós-Graduação em Comunicação da Pontifícia Universidade Católica do Rio de Janeiro - PUC-RJ, Brasil.
Habitus antropológico no café da manhã

Numa manhã de junho, ainda com pensamentos adormecidos e congelados pelo frio das seis horas da manhã, ponho-me a preparar, como todos os dias, a mistura de Leite Ninho com Toddy para minhas filhas. Há tantos anos elaborando esta alquimia, posso afirmar, com orgulho, que sou uma especialista na bebida: encontrei o ponto certo, numa engenhosa prática dividida em duas fases de elaboração, que dissolve tudo sem deixar sólidos, o que me economiza o tempo de um incômodo liquidificador ou de uma emergencial peneira para separar líquido de indesejados grãos. Penso, enquanto isso, que talvez as adolescentes já estejam grandes demais para beber Leite Ninho, ao contrário da caçula. Será que não está na hora de comprar leite Longa Vida para elas? Será que já não está na hora de incentivá-las a tomar café com leite? 0 fato de eu não tomar café não estaria me conduzindo para uma atitude ditatorial de impor uma prática pouco comum às duas? E por que eu me questionei sobre o Leite Ninho não ser mais bebida para adolescentes? 0 Toddy não estaria na mesma categoria? E o café, a que 
categoria pertence? Diante de tantas perguntas, evidentemente já desperto do sono e ponho-me a tentar estabelecer relações com algumas teorias da antropologia que nos ajudam a compreender 0 significado de algumas crenças, práticas e valores naturalizados por nós e que, muitas vezes, têm muito a revelar sobre quem somos.

0 cotidiano não é nada ordinário. Ao contrário, é dele, ou de sua complexidade, que se nutrem as Ciências Sociais modernas, com perspectivas mais interpretativas e abrangentes, instituídas em meados do século XX, especialmente através da Antropologia e da História Social (Williams, 2011; Geertz, 1989).

É no dia a dia da vida ordinária que colocamos em prática a cultura que nos une a todos e que norteia nossas trajetórias individuais e coletivas em sociedade. Estar atenta aos detalhes, portanto, faz parte de minha "natureza" antropológica, do meu oficio, que me fez internalizar determinados fazeres profissionais e que se tornaram um habitus - 0 social incorporado, como quer Bourdieu (2008) nem sempre bem-vindo, já que há determinadas situações cotidianas que só são boas ou importantes se não forem analisadas à luz de qualquer teoria. Como são, por exemplo, determinados rituais e mitos que nos divertem - e, em certo sentido, nos alienam.

0 objetivo deste artigo é analisar aspectos desta vida ordinária que revelam muito sobre quem somos, que estão presentes no consumo e nas representações de coisas do dia a dia - coisas materiais e coisas imateriais. Coisas que, de alguma forma, estão presentes em uma espécie de "sociedade dos objetos", que funciona tal qual a nossa sociedade, como que em uma camada simbólica tecida com as relações humanas. Trata-se de uma "vida material" ou "civilização material", denominada por Braudel (apud Dant, 2006), mais tarde explorada por Dant (2006) para desenvolver a ideia de "interação material", ou seja, relações concretas entre pessoas e coisas, especialmente através do corpo. A presente discussão busca contribuir para os estudos da Cultura Material em diálogo com a Comunicação, em uma perspectiva antropológica, inspirada pelas teorias de Daniel Miller (1987), para quem coisas e pessoas vinculam-se existencialmente através da "objetificação", conceito hegeliano que conduz todas as pesquisas etnográficas do antropólogo britânico. Assim sendo, as representações midiáticas do café e do chocolate são aqui tomadas como objetos de análise, orientando as reflexões para a compreensão, mais especificamente, dos marcadores sociais que estabelecem fronteiras geracionais entre adultos e crianças através do consumo e de suas narrativas construídas pela publicidade. A metodologia usada baseia-se na análise interpretativa do conteúdo de anúncios impressos, publicados em revistas brasileiras e disponibilizados nos mecanismos de busca do Google.

Considerando, portanto, a abordagem que traz a cultura material para o debate nas Ciências Sociais que rompe com a clássica dicotomia entre humanidade e materialidade (Miller, 1987; Appadurai, 2010), em que a primeira é positiva e a segunda, negativa, a vida cotidiana torna-se lugar privilegiado 
para a expansão da noção de cultura como algo que se dá em sociedade, de forma legítima, em todos os níveis, inclusive no popular, já tão negligenciado pela "alta cultura" (Hoggart, 1973; Williams, 2011; Hall, 1997). Trata-se de afiar o habitus antropológico e, algumas vezes, etnográfico para 0 campo que nos é mais familiar, e não somente para aqueles geograficamente mais distantes, que deram lugar às pesquisas dos "pais" da Antropologia, como Bronislaw Malinovski, entre outros.

Há muito o que se aprender com o café da manhã.

\section{Breve introdução à cultura material, na perspectiva antropológica de Daniel Miller}

Coisas são inerentes às pessoas e vice-versa (Miller, 1987). Para se viver em sociedade, para viver $a$ sociedade, com seus valores, crenças, práticas e rituais, precisamos das coisas. E as coisas também formam uma espécie de sociedade, pois entre elas se estabelecem relações sociais que precisam de nós, pessoas, para colocá-las em movimento, em circulação, dentro da vida ordinária. $0 u$, no limite, sendo retiradas de circulação, ou desmercantilizadas, para se tornarem objeto de devoção, como aquelas que encontramos nos museus, templos religiosos, salas de colecionadores de artes e de relíquias
(Kopytoff, 2010). As coisas, enquanto mercadorias, têm uma vida social (Appadurai, 2010).

É importante compreender que o consumo, tal qual 0 entendemos dentro das sociedades modernas ocidentais, é uma instância (fundamental, mas não exclusiva) da cultura material. Enquanto o consumo é um sistema de classificação e de significação dos bens (Douglas e Isherwood, 2004; Rocha, 2010), a cultura material é 0 lugar que 0 abrange, dentro do qual ele ganha vida. 0 consumo não vive sem a cultura material, já a cultura material está para além dele.

Para Miller (1987), há uma construção mútua entre sujeito e objeto. Aproximando-se da filosofia de Hegel, 0 antropólogo explora o conceito de "objetificação", o qual será aplicado em todas as suas teorias e pesquisas etnográficas sobre os usos de celular (Miller, 2006), sobre as compras de supermercado (Miller, 2002) ou sobre a calça jeans (Miller e Woodward, 2012). Grosso modo, a "objetificação" é 0 resultado de um processo de construção existencial, que se confere um significado e um valor a algo material, a partir da vontade humana exteriorizada e, depois, reincorporada no sujeito.

Neste livro, o processo de objetificação será usado para considerar o relacionamento entre, de um lado, o sujeito que é humano (e normalmente coletivo), e do outro, primeiro, a cultura como toda forma exterior e, depois, 0 artefato como 0 objeto material humanizado (Miller, 1987, p. 28)'.

Tradução do original: "In this book, the process of objectification will be used to consider the relationship between on the one hand a subject which is human (and usually collective), and on the other, first, culture as all external form, and later, the artefact as the humanly produced material object". 
Como resultado de suas investigações, invariavelmente Miller busca a objetificação na cultura, em seu contexto local, como quando, por exemplo, afirma que o blue jeans é a objetificação do "ordinário" no contexto da cidade de Londres (Miller e Woodward, 2012), ou que o Facebook é a objetificação da "fofoca" na cultura trinidense (Miller, 2011).

Em um de seus textos, Miller (1994) reflete sobre os artefatos e o significado das coisas, elaborando uma espécie de "defesa" dos estudos da cultura material e da necessidade de se problematizar a "fisicalidade" das coisas, elaborando-a em suas relações com as pessoas. Neste esforço, então, aborda a questão do "ordenamento" como parte da constituição da cultura, em um processo de atribuição de significado. A ordem e a classificação determinam os significados dos objetos: "Se o significado dos objetos deriva das ordens nas quais eles estão incorporados, então 0 mesmo artefato pode mudar suas implicações simplesmente por ser introduzido numa nova ordem" (Miller, 1994, p. 400)2. Noutras palavras, os sistemas de relações sociais constroem as matrizes culturais através das quais os objetos serão ordenados. Revelando-se os significados dos objetos elaborados dentro de tais sistemas de relações sociais, por consequência, revelamse, também, tais matrizes culturais. Evocando o trabalho de Lévi-Strauss sobre máscaras e mitos,
Miller (1994, p. 400) afirma que "os objetos de uma sociedade são vistos como derivando seus significados não apenas de suas relações de oposição um com o outro, mas das formas nas quais este sistema de relações provoca inversão parcial quando cruza fronteiras de sociedades vizinhas". Ao mesmo tempo em que aponta 0 estruturalismo como a abordagem que tornou a "ordem das coisas" central para compreender a cultura humana, já que se constitui, por natureza, a partir de pares de oposição, reiterando, inclusive, sua importância para os estudos da cultura material para 0 exame de padrões culturais ali presentes, Miller relativiza o seu uso em estudos recentes, privilegiando um olhar antropológico mais interpretativo e contextual, liberado dos métodos formais e estritos aos quais tal perspectiva lévi-straussiana se afilia.

Um dos expoentes do pensamento estruturalista e que fundamentou uma das teorias mais importantes para os estudos da antropologia moderna é Marshall Sahlins (2003). Juntamente com Daniel Miller, algumas das ideias deste autor norteiam a análise desta discussão a respeito do café e do chocolate, mesmo conhecendo as limitações apontadas pelo antropólogo britânico a respeito da perspectiva estruturalista. Assumindose 0 risco de que os pares de oposição que serão usados mais à frente possam restringir, talvez, a reflexão a uma abstração formal e restrita 
metodologicamente, acredita-se que o ganho ainda será maior do que as perdas, uma vez que ambos privilegiam a materialidade como parte do social, afastando-se de abordagens que estabelecem uma dicotomia entre coisas e pessoas.

\section{Uma dose de estruturalismo com café - ou chocolate?}

A célebre frase de Lévi-Strauss, hoje lugar-comum em epígrafes de inúmeras dissertações e teses das Ciências Sociais, "Compreendemos enfim que as espécies naturais não são escolhidas por 'serem boas para comer', mas por serem 'boas para pensar" (Lévi-Strauss, 1980, p. 166), é uma das bases do livro Cultura e Razão Prática, de Marshall Sahlins (2003 [1976]). Se, de um lado, Lévi-Strauss reúne teorias que demonstram que o pensamento selvagem, longe de ser uma lógica de pensamento dos povos ditos "primitivos" para compreender e controlar os fenômenos do mundo que os cerca (Lévi-Strauss, 1989 [1962]), é, na verdade, um sistema de classificação também presente nos povos denominados "civilizados" que ordena em categorias da natureza as formas culturais vividas em sociedade, de outro, Marshall Sahlins (2003) empreende uma densa discussão sobre tais ideias para analisar o consumo de carne na sociedade norte-americana.

Em seu livro, Sahlins (2003) critica o pensamento corrente, à época de seus escritos, de que as culturas são orientadas por atividades práticas e por interesses meramente utilitários, em que predomina a lógica econômica, defendendo que, no lugar da "razão prática", uma outra, que ele denomina de "simbólica", orienta todo o sistema de classificação que acaba por estabelecer estreitas relações entre o mundo material e as pessoas. Para ele, "0 capitalismo não é pura racionalidade. É uma forma definida de ordem cultural; ou uma ordem cultural agindo de forma particular" (Sahlins, 2003, p. 185). Afirma o teórico que tal dimensão simbólica não é percebida pelos indivíduos e instituições, pois a sociedade moderna ocidental é dominada pela racionalidade e pela visão utilitarista do consumo. Em sendo desta maneira, já na sua produção as coisas materiais seriam, ainda que à sombra de tal dominação, significadas através de um processo preexistente de apropriação simbólica da natureza. Assim é que, como demonstra Sahlins, a sociedade norte-americana constrói uma complexa estrutura econômica alimentícia em torno da centralidade da carne, a qual passa a ser classificada a partir de sua comestibilidade. As carnes de cachorro e de cavalo são interditadas ao consumo, pois trata-se de animais muito próximos do ambiente doméstico, aos quais, inclusive, são atribuídos nomes de pessoas. Já as carnes de boi e de porco pertencem a categorias de alimentos comestíveis, com os quais não há, obrigatoriamente, uma relação de afeto por parte dos seres humanos. A despeito de uma lógica utilitarista, que apontaria para poucas distinções nutricionais entre estes tipos de carnes, por exemplo, naturaliza-se o consumo de umas em detrimento de outras, pois às categorias 
de alimentos associam-se categorias sociais e culturais. 0 estruturalismo lévi-straussiano de Sahlins é aplicado não apenas com relação ao alimento, mas também ao vestuário, e, por meio de esquemas de contrastes binários entre os significantes, vão se configurando relações entre as coisas e os seus significados, revelando as matrizes dos sistemas classificatórios da sociedade por ele observada. A título de exemplo, o autor desenha um "esquema de funções significadas no vestuário americano" (Sahlins, 2003, p. 186), em que se opõem as categorias "lazer" x "trabalho" para que, a partir delas, outras sejam colocadas em relação também binária ("ativo/doméstico" x "burocrático/manual", respectivamente, e daí para outros níveis), a fim de que se compreendam de que maneira os diferentes tipos de roupas se distribuem entre polos que vão do "marcado ou cerimonial" até 0 "não-marcado ou de trabalho". Este mesmo exercício é feito entre "masculino x feminino", gerando "lã x seda", "brim x algodão", "pesado x leve", o que vai revelando, entre outros aspectos, os papéis de gênero socialmente aceitos. Sahlins explica que:

Assim procede a economia, como locus institucional dominante: produz não somente objetos para sujeitos apropriados, como sujeitos para objetos apropriados. Ela joga uma classificação sobre toda a superestrutura cultural, ordenando as distinções de outros setores através da oposição de seus próprios setores - exatamente como ela usa essas distinções para seus próprios propósitos (lucros). Ela produz o que pode ser chamado de "sinapses simbólicas". Conjunções de oposições de planos culturais distintos que então tomam a forma de diferenciações homólogas - como trabalho/descanso: dia útil/ fim de semana; ou área comercial/bairro residencial: impersonalismo/familiaridade. Algumas dessas proporções são construídas por analogia como a combinação para vestuário entre adolescente/adulto:trabalhador/capitalista (Sahlins, 2003, p. 186).

De forma inconsciente, tais conexões de sentido já estavam previamente sedimentadas na vida e na práxis sociais. A função do antropólogo, segundo o autor, é análoga àquela dos que denomina de "mercenários do símbolo" (Sahlins, 2003, p. 215), ou seja, os pesquisadores de mercado, publicitários ou designers de moda: descobrir a ordenação presente neste sistema de significados, atuando no estabelecimento das sinapses e correspondências entre a ordem cultural e a ordem material. E é exatamente isso que será buscado na próxima seção.

\section{Representações midiáticas na Publicidade}
A análise dos anúncios será norteada pela concepção de "representação social" como um fenômeno dinâmico, interacional e comunicacional, em que participam diferentes atores sociais, dentre eles, e de forma fundamental, a mídia (Moscovici, 2011). Por "representação", entenda-se, também, a forma construcionista dada a uma relação simbólica estabelecida entre objeto e imagem, ambos, aqui, referidos em um sentido mais amplo (Hall, 1997). Para fins desta discussão, será usada a expressão "representação midiática", a qual concilia as duas definições de Moscovici e Hall, apontando para a especificidade da contribuição da mídia na 
construção da "representação social" que circula nas interações da vida cotidiana.

Das contribuições de Moscovici (2011) para a presente análise, vale ainda destacar as duas fases do processo de construção das representações sociais, quais sejam, a "ancoragem" e a "objetivação": a primeira é a busca de aproximação com representações "familiares" anteriores, caso o objeto em questão seja ainda "não-familiar"; a segunda fase é sua associação, já ancorada, com uma imagem, ideia ou qualquer outra forma simbólica expressiva e compreendida pelo senso comum.

Às teorias de Hall, acrescente-se ainda a definição da "identidade", que é dada, sempre, de forma relacional com a diferença: 0 amarelo é amarelo porque não é vermelho, ou verde, ou azul, por exemplo (Woodward, 2000).

Isto posto, parte-se, então, para a análise das representações midiáticas do café (em pó e solúvel) e do chocolate (solúvel) em anúncios publicitários impressos, levando em conta (1) a natureza da publicidade como narrativa que atribui significação às coisas materiais, (2) 0 binarismo das coisas em suas correlações com categorias culturais e (3) as demais categorias de alimentos similares, as quais, juntas, elaboram um "mapa de significados" (Hall, 1997), que colabora para a compreensão de todo o processo de significação, tal qual se propõe neste artigo.
Para fins de recorte do corpus da pesquisa, foram coletados anúncios publicitários impressos de um tipo específico de café e de chocolate: em pó (no caso do café, torrado e moído, para ser preparado com água, no coador de pano ou de papel, ou ainda na cafeteira; o chocolate em pó deve ser usado apenas para fins culinários e não como bebida, tendo sido, portanto, excluído desta análise) e solúvel (tanto para o café como para o chocolate, devendo ser misturados com água e leite, respectivamente; o café solúvel também pode ser acrescentado ao leite). Tal pesquisa documental foi realizada pela internet, no mecanismo de busca Google, com a entrada "anúncio café", "publicidade café", "anúncio Toddy" e "publicidade Nescau". Muitas das peças encontradas, porém, não foram veiculadas, pertencendo a páginas que são "portfólio" de profissionais e estudantes de Publicidade, tendo sido, desse modo, descartados, e mantidos apenas os anúncios antigos publicados. Da mesma forma, foi realizada uma busca no Acervo Digital - Veja.com ${ }^{3}$ No total, são doze peças analisadas.

Em um primeiro momento, analisam-se as imagens e os textos para que, depois, se estabeleçam os pares de oposição que ajudarão na correspondência com categorias sociais. Evidentemente, tanto a escolha dos anúncios como a interpretação de suas narrativas são decisões arbitrárias da pesquisadora, ainda que dentro de um rigor metodológico reflexivo de estranhamento e distanciamento, de acordo com os objetivos propostos. 
No anúncio do ano de 1949 (Figura 1), 0

achocolatado Toddy, que chegou ao Brasil em 1933, é associado às ideias de "saúde" e "energia", palavras que aparecem no rótulo, junto à marca, além de "alegria", presente no título. No texto, o chocolate é apresentado como ideal para ser tomado "gelado no verão e quente no inverno", e como alimento que "proporciona ao organismo os elementos nutritivos que lhe dão vigor e bem-estar". Além disso, a peça publicitária destaca "como é gostoso!". A ilustração de um garoto brincando com um cachorro em um ambiente campestre não deixa dúvidas de que Toddy é uma bebida para crianças.

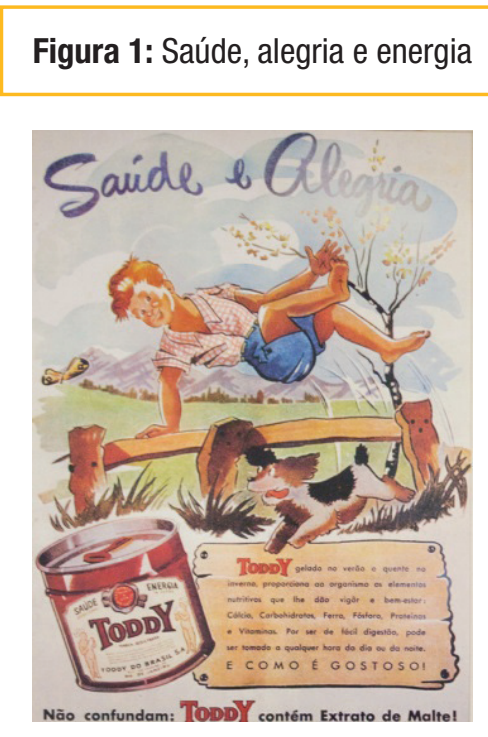

Fonte: Site "Empório da Criação"4

No segundo anúncio analisado (Figura 2), sem informação de data, o pote de plástico de Toddy aparece ladeado por uma xícara aparentemente com uma bebida quente, um copo de vidro com 0 achocolatado gelado e um canudo, e, atrás destes elementos, uma bola, um estilingue e um alvo com dardos. Mais uma vez, Toddy é relacionado com 0 universo infantil e masculino. 0 texto afirma que a bebida contém "todas as substâncias necessárias para gerar energia".

Figura 2: Força, energia e garotada

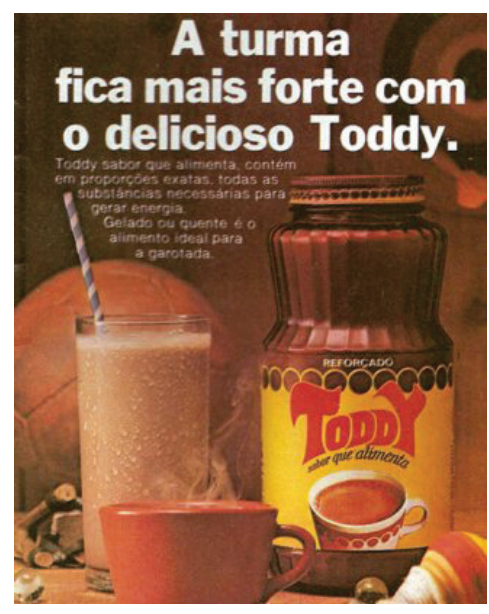

Fonte: Site lg - Economia ${ }^{5}$

0 anúncio da vaca com fones de ouvido (Figura 3), bem mais recente (2004), já revela uma mensagem que se preocupa mais com o sabor do que com especificidades nutricionais. A figura da vaca ainda aparece nas peças publicitárias da marca Toddy atuais, associando-a com 0 campo e com a natureza, tal qual aquele de

Disponível em http://www.emporiumdacriacao.com.br/blog/2013/05/13/emporium-no-tempo-4/. Acessado em 17 de junho de 2016.

Disponível em http://economia.ig.com.br/empresas/industria/toddy-chegou-ao-brasil-em-1933/n1237788306534.html. Acessado em 17 de junho de 2016. 
1949. A bebida é apresentada, aqui, como "0 chocolate que liga", ideia que é reforçada pela imagem do animal, aparentemente "ligado" no mundo humano, através da música.

\section{Figura 3: 0 chocolate que liga}

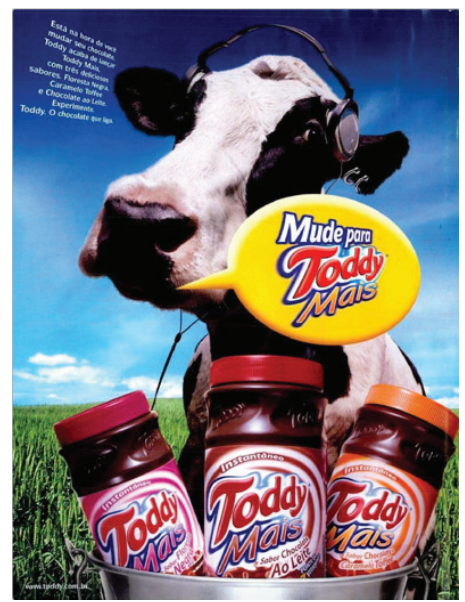

Fonte: Revista Veja - 6/10/2004, p. 144

A peça publicitária do Nescau, de 1999, concorrente direta da marca Toddy, ocupa uma página dupla da revista. Mais uma vez, é um garoto que aparece bebendo, com o típico "bigodinho" normalmente deixado pelo leite sobre a boca, mas que aqui é marrom, da cor do chocolate. 0 título afirma que "Nestlé, para mim, é um copão de Nescau maior que eu". A narrativa é na primeira pessoa, provavelmente de um atual adulto que já foi o menino da fotografia, em que ele relata como recebia alegre, quando criança, o copo de achocolatado que sua mãe, com todo o carinho, preparava para ele, sentado na cadeira, "com os pezinhos balançando", em contraste com o copo "grandão, grandão". A bebida é relacionada aqui com as ideias de "força", "poder", "energia" e "festa".
Figura 4: Força, energia e festa

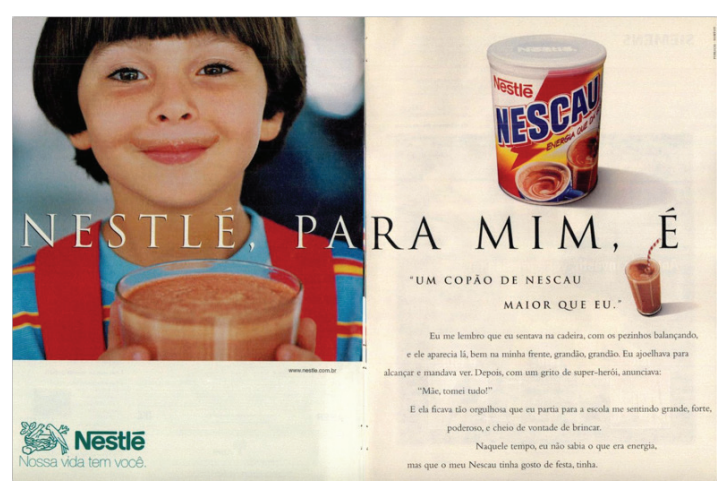

Fonte: Revista Veja - 9/06/1999, p. 18-19

Nescau é representado, no anúncio sem data da publicidade visivelmente mais antiga, como parte dos cuidados da mãe com um casal de filhos (Figura 5). 0 texto destaca as vitaminas que contribuem para a saúde e o sabor, que traz, por consequência, o êxito nos estudos e nos esportes. Por ser instantânea, a bebida é apresentada como fácil de ser preparada, inclusive pelas próprias crianças. Quente ou fria, a bebida é nutritiva e tem "gosto de festa".

Figura 5: Estudos, esportes, vitaminas e festa

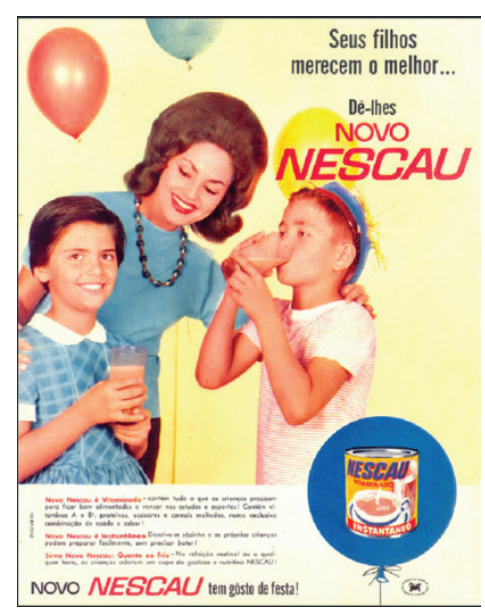

Fonte: Página \#blogdakad0 ${ }^{6}$ 
0 recente anúncio de Nescau (Figura 6) indica que a bebida proporciona energia para "aceitar ainda mais desafios" em uma vida dividida entre a "balada" e as "provas" de uma adolescente, insinuada pela mão feminina e jovem que segura um grande copo da bebida em movimento, que transborda. 0 título, "Balada na quinta, prova na sexta", é complementado pelo subtítulo "Desafio aceito", mais abaixo, com um texto que explica que o Nescau 2.0 é o que motiva para esta rotina cheia e que garante "energia" para esse e qualquer outro desafio.

Figura 6: Balada, prova, energia e desafios

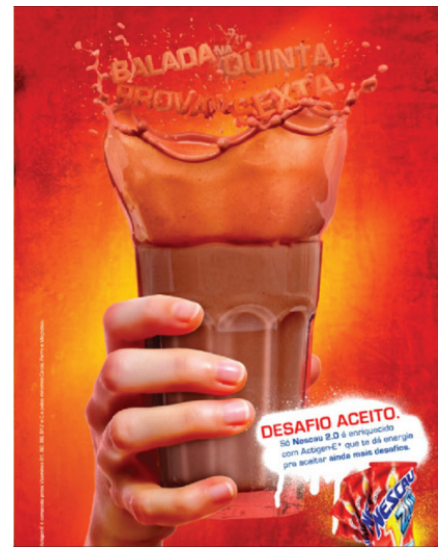

Fonte: Página \#blogdakad0 ${ }^{7}$

0 sétimo e último anúncio de achocolatado, agora da marca Ovomaltine, data, segundo a fonte, dos anos 1940 (Figura 7). Nas imagens, uma mãe com ar cansado segura seu filho "já crescido" no colo, tentando fazê-lo dormir. 0 título "Êle só quer a mamãe..." reforça a ideia. E, mais abaixo, em um box, 0 "Dr. Francisco Benedetti" atesta o valor nutritivo da bebida, que promete acabar com a "deficiência alimentar", que traz como consequência a insônia e a pouca disposição para os estudos e as brincadeiras. Ovomaltine "desperta 0 vigor" nas crianças.

Figura 7: Mamãe, médicos e crianças nutridas

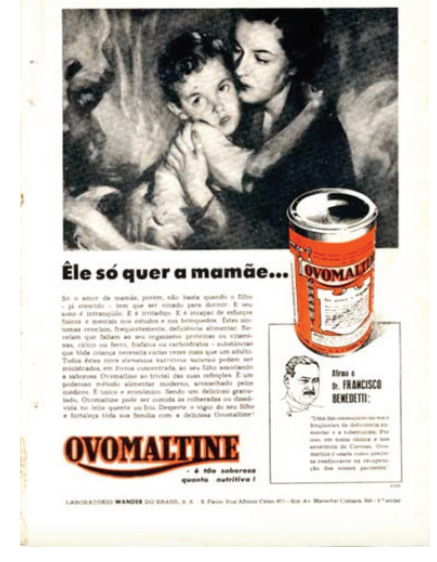

Fonte: Site Propagandas Históricas ${ }^{8}$

A narrativa publicitária das peças até aqui discutidas baseia-se, invariavelmente, no discurso da "energia" para crianças e adolescentes. São evocadas, também, palavras como "nutritivo", "força", "vitaminas", "festa", "sabor" e "gostoso". 0 chocolate, através do caráter pedagógico da publicidade, nos é apresentado como um alimento que é fonte de energia, sem que esta qualidade seja racionalmente explicada. Mesmo nos anúncios 
mais antigos, datados dos anos 1940, quando os textos publicitários usavam uma retórica racional para explicar seus produtos, tendo sido inclusive um deles referendado por um suposto médico, o fator "fonte de energia" não é explicado cientificamente. A publicidade apenas nos informa que é. Observa-se que, nos anúncios mais recentes, há uma "ancoragem" (Moscovici, 2011) nesta crença, a qual é ainda um forte apelo persuasivo. Há, também, principalmente nas peças mais antigas aqui investigadas, a presença materna como aquela que fornece 0 alimento para seus filhos, que o recebem com alegria, devolvendo, em troca, boas noites de sono, uma vida agitada pelas brincadeiras e exitosa nos estudos, em um círculo virtuoso da reciprocidade (Mauss, 2011).

0 presente trabalho encaminha-se, agora, para a publicidade de café.

Figura 8: Novo, rápido, prático.

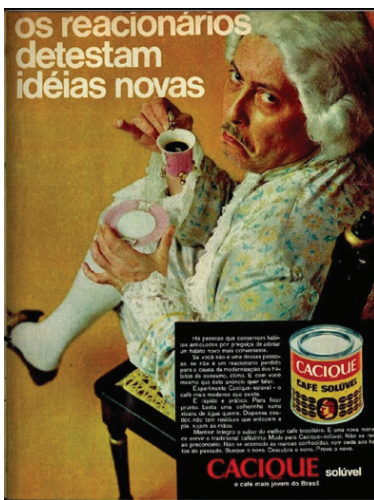

Fonte: Blog Memória Oswaldo Hernandez ${ }^{9}$
0 primeiro anúncio de café escolhido para análise é da marca Cacique (Figura 8). Trata-se de uma peça dos anos 1970, que apresenta o produto com um fim bastante específico: apresentá-lo em uma forma mais "moderna" e "inovadora" para pessoas que não têm "preconceito" e nem são "reacionárias", ou seja, na forma solúvel. Até ali, o brasileiro, tradicionalmente consumidor do melhor café do mundo, tinha no seu dia a dia o hábito de preparar a bebida com coador de pano - 0 que de forma alguma foi abandonado na rotina dos consumidores daqui. Associa-se 0 "tradicional cafezinho" sempre ao "sabor" e a qualidades como "prático", "moderno" e "rápido". A fotografia que ilustra o anúncio é um homem com trajes e perucas do século XIX, que lembra a nobreza europeia, sentado em uma cadeira de palhinha e madeira, que aparentemente olha por sobre os ombros para o leitor, de modo desconfiado, sob o título "Os reacionários detestam idéias novas". 0 slogan do produto é "0 café mais jovem do Brasil".

Figura 9: Prática feminina x Rebeldia masculina

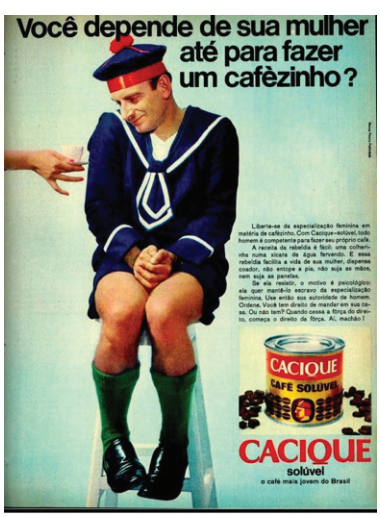

Fonte: Blog Memória Oswaldo Hernandez ${ }^{10}$

Disponível em http://memoriasoswaldohernandez.blogspot.com.br/2012/10/anuncios-dos-anos-70-de-diversos.html. Acessado em 17 de junho de 2016.

10 Disponível em http://memoriasoswaldohernandez.blogspot.com.br/2012/10/anuncios-dos-anos-70-de-diversos.html. Acessado em 17 de junho de 2016. 
Outro anúncio da mesma campanha do Café

Cacique Solúvel (Figura 9) traz um homem adulto vestido com uma roupa infantil, quase caricatural, de chapéu e gravata no estilo marinheiro, sentado em um banco alto, o que 0 deixa com os pés sem alcançar o chão, em uma posição tímida, olhando para uma mão feminina que oferece a ele uma xícara de cafezinho. 0 título "Você depende de sua mulher até para fazer um cafèzinho?" provoca 0 leitor com humor e ironia, para introduzir um texto que revela os valores masculinos ali implícitos: há uma "especialização feminina em matéria de cafezinho", a qual parece esconder uma intenção maldosa de manter "escravo" o marido, "machão", que tem "autoridade", "ordena" e "manda em casa". 0 café solúvel, portanto, é apresentado como um ato de "liberdade" e "rebeldia", que permite que o homem prepare seu próprio cafezinho ou, ainda, que facilita a vida da mulher que não precisa mais sujar as mãos, nem as panelas.

Figura 10: Forte, encorpado e econômico

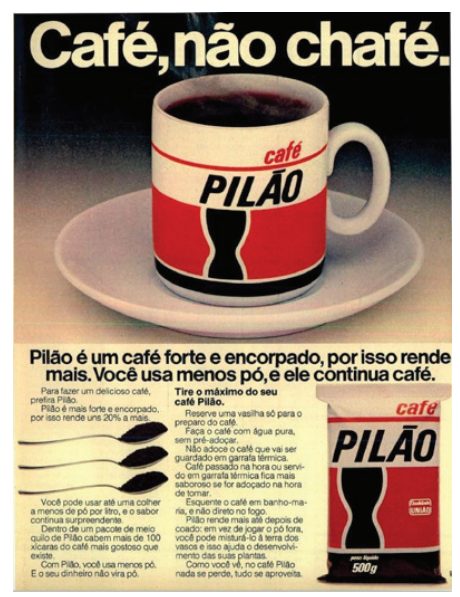

Fonte: Revista Veja - 14/04/1985, p. 51
Os três próximos anúncios são do café da marca Pilão. 0 primeiro deles (Figura 10), de 1985, tem como título "Café, não chafé", fazendo referência a uma expressão popular que indica preferência pelo café mais forte, com menos água, o que estaria associado ao chá. As imagens trazem uma xícara de café com a marca Pilão, três colheres com o pó do café e, "assinando" a peça, a embalagem do produto. Os subtítulos "Pilão é um café forte e encorpado, por isso rende mais. Você usa menos pó, e ele continua café" e "Tire o máximo de seu café Pilão" reforçam a intenção do título. 0 texto é um conjunto de dicas e conselhos para o máximo aproveitamento do produto, com números, percentuais e referência ao dinheiro gasto, inclusive após o consumo, como adubo para plantas. Com abordagem bastante racional, 0 apelo da peça publicitária reside mais na lógica econômica, mas não abre mão das característas "forte" e "encorpado", que é o que, na verdade, garante que tais dicas e conselhos valham a pena de serem seguidos. Apenas a título de contextualização, em 1985, o país vivia uma grave crise econômica.

Figura 11: Aroma, frescor e sabor original

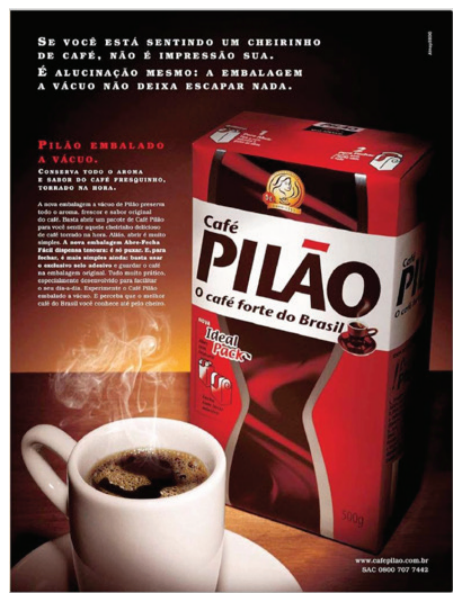

Fonte: Revista Veja - 24/08/2005, p. 131 
0 segundo anúncio do Café Pilão (Figura 11), de 2005, é um apelo para a sensorialidade. 0 título "Se você está sentindo um cheirinho de café, não é impressão sua. É alucinação mesmo: a embalagem a vácuo não deixa escapar nada". A imagem é a embalagem do Café Pilão com uma xícara cheia da bebida fumegante. 0 subtítulo "Pilão embalado a vácuo: conserva todo 0 aroma e sabor do café fresquinho, torrado na hora" introduz um texto que, como 0 anterior, embora com um hiato de 20 anos de publicação, conserva o mesmo tom pedagógico de como abrir a embalagem a vácuo, destacando o "cheirinho delicioso de café torrado na hora" e, ao mesmo tempo, a nova embalagem "abre-fecha" que é "simples", "prático", "para facilitar o seu dia-a-dia". Fica evidente, nos anúncios até aqui abordados, que há uma noção de "trabalho" presente no preparo da bebida.

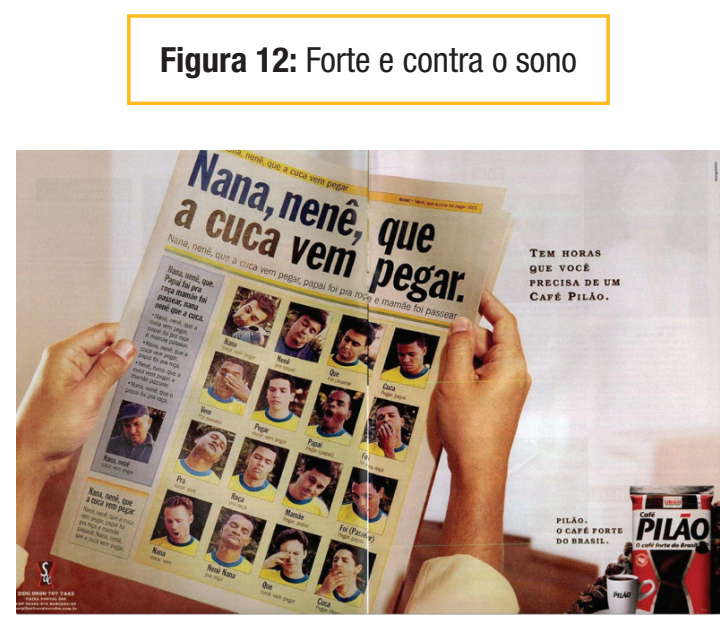

Fonte: Revista Veja - 01/08/2001, p. 112-113.

0 último anúncio publicitário a ser analisado (Figura 12) é exemplar daquilo que circula, nas conversas cotidianas, como a mais familiar das representações sociais (Moscovici, 2011) sobre o café: a de uma bebida que tira o sono. A peça publicitária mostra mãos masculinas segurando um jornal que tem como manchete a frase "Nana, nenê, que a cuca vem pegar", o que se repete em todos os subtítulos e textos do suposto jornal, cuja matéria de capa é a foto de jogadores de futebol com uma camisa verde e amarela visivelmente com muito sono ou até dormindo. Conclui-se que, pela data de publicação, o bom humor do anúncio está na crítica ao recente mau desempenho da seleção brasileira na Copa América daquele ano de 2001, ao ser eliminada nas quartas de final pelo time de Honduras por 2 x 0.0 texto do jornal, "Tem horas que você precisa de um Café Pilão", tem um duplo sentido, ao referir-se ao desânimo do torcedor pela derrota e ao sono que o jornal daquele dia provoca com a notícia da primeira página. Assinando 0 anúncio, uma fotografia da embalagem do Café Pilão com uma xícara e 0 slogan "Pilão. 0 café forte do Brasil".

0 que os cinco anúncios de café aqui analisados revelam é uma narrativa com abordagem racional associada a elementos sensoriais relacionados ao sabor e ao aroma da bebida. Percebe-se, também, que não há nenhuma referência a crianças nas peças publicitárias analisadas e as mulheres aparecem em apenas em um deles ${ }^{11}$, mais antigo, como aquela que faz e serve o café ao seu marido.

11 A ausência de mulheres em anúncios de café, porém, não pode ser generalizada. Foram encontradas outras peças publicitárias em que a mulher aparece tomando café, invariavelmente de olhos fechados, sentindo 0 sabor e 0 cheiro da bebida, normalmente não em xícaras pequenas, mas sim em canecas maiores, remetendo a uma sensação de conforto do lar. 
Infere-se, portanto, que o café é uma bebida que pertence, simbolicamente, ao universo masculino adulto. As palavras que estão mais associadas à bebida são "forte", "sabor", "encorpado", "prático" e "fresquinho".

Elaboramos, para efeito de análise, o Quadro 1, em que se comparam os elementos imagéticos e textuais que aparecem nos 12 anúncios observados.

\section{Quadro 1: Chocolate x Café}

\begin{tabular}{|c|c|}
\hline CHOCOLATE & CAFÉ \\
\hline criança & adulto \\
\hline energia & força \\
\hline feminino & masculino \\
\hline nutrição & sabor \\
\hline alegria, festa & despertar \\
\hline diversão & trabalho \\
\hline emoção & razão \\
\hline gostoso & encorpado \\
\hline leite & água \\
\hline frio & quente \\
\hline
\end{tabular}

A publicidade, como ofício dos publicitários, profissionais que, como afirma Sahlins (2003), são especialistas em estabelecer correspondências entre a ordem cultural e a ordem material em um sistema de significados, constrói as narrativas dos anúncios que servem de representações midiáticas significantes da relação entre produtos e categorias de pensamento socialmente construídas. Ou o que, para Rocha (2010), é um "operador totêmico". 0 chocolate, parte da cultura material, relaciona-se com outros tipos de bebida, como o café, os diferentes tipos de chá, os sucos, as águas, os refrigerantes, os energéticos, as vitaminas, os leites. Neste sistema de classificação, ocupa um lugar distintivo, assim como 0 café e as demais bebidas aqui mencionadas. Os consumidores, por sua vez, como parte da cultura humana, relacionam-se com os produtos dentro do tecido simbólico, tramado através de categorias carregadas de significado. A ordem cultural e a ordem material encontramse nesta interação entre coisas e pessoas, materialidade e humanidade, a qual ganha forma através das convenções linguísticas, elaboradas e reelaboradas por meio da conversa, mas também, e principalmente, das representações midiáticas.

0 objetivo deste artigo, portanto, é fazer revelar possibilidades de interpretação que identifiquem este lugar simbólico do chocolate, não através da "razão prática" e utilitária presente no discurso científico, mas por meio da "cultura" (Sahlins, 2003), presente no discurso publicitário.

0 chocolate solúvel, desse modo, é uma bebida que pertence a um mundo infantil ou, no máximo, adolescente. Sua proximidade com este universo 0 associa ainda muito à figura da mãe e, por consequência, a uma dada feminilidade. 0 produto legitima-se através da energia que proporciona às crianças, muito mais do que por ser, simplesmente, gostoso. Mães devem, afinal, se preocupar com o bem-estar da família, sacrificando-se para este fim, e sua recompensa é o reconhecimento como boa dona de casa (Miller, 2002). 0 chocolate é nutritivo, pois está sempre misturado com o mais nutritivo (e maternal) 
dos alimentos: 0 leite. Trata-se da forma mais divertida e festiva de alimentar os filhos e, por esse motivo, é mais comum encontrá-lo na versão gelada, embora possa ser servido quente, que lembra 0 colo e 0 aconchego da família. 0 alimento gelado, como o sorvete, por exemplo, é festivo e não demanda muita atenção e cuidado das mães, pois não machuca, não queima a boca. 0 quente, ao contrário, requer atenção e deve ser consumido sob os olhares de um adulto, em casa, que vai monitorar a temperatura do alimento servido, para evitar qualquer tipo de acidente.

0 café em pó ou solúvel apresenta, já nestas duas formas de preparo, diferenças importantes: 0 primeiro exige mais trabalho dispendido e 0 segundo, é um facilitador para a vida prática diária. Sendo assim, o café em pó é uma especialidade feminina para ser servida ao homem, na figura do marido, pelo menos no contexto dos anúncios analisados, pouco afeitos à cozinha. De qualquer modo, o preparo do café demanda, de qualquer forma, um trabalho que não é mais o da mãe: no máximo, da esposa. Trata- se de uma bebida para adultos, pois que é forte, encorpada e servida quente. Ainda com relação ao preparo, parte importante de sua identidade frente a outros tipos de bebida, inclusive ao chocolate, não pode ser feito sem água. 0 famoso e tradicional cafezinho é, com efeito, pó e água, muitas vezes abrindo-se mão, inclusive, de qualquer tipo de adoçantes. Quanto mais amargo, mais masculino. 0 leite é outra alternativa para a mistura, mas nunca está presente na publicidade do café. 0 café-com-leite, portanto, é outra categoria de bebida, dentro do sistema simbólico material que nos serve aqui de análise. Sua propriedade mais popular é fazer despertar. Recorre-se à bebida, com frequência, sempre que se quer manter acordado, fora de casa - em situações de trabalho, principalmente.

Tal análise pode ainda avançar para outra, quando relacionamos as categorias chocolate e café, da ordem material, com algumas categorias da ordem cultural. 0 Quadro 2 propõe-se a representar estas relações, através de um esquema inspirado pelo estruturalismo de Sahlins (2003): 
Quadro 2: Categorias materiais $x$ Categorias culturais

Leite Chocolate Café-com-leite
Criança $===================================>$ Adulto
Mãe $======================================>$ Pai
Copo $=====================================>$ Xícara
Gostoso $===================================>$ Encorpado
Feminino $==================================>$ Masculino
Energia $==========================================>$ Força
Família $==========================================>$ Trabalho
Emoção $===========================================>$ Razão
Leite $======================================>$ Água
Natureza $=================================>$ Sociedade

A próxima seção desenvolverá uma reflexão a partir de tais correspondências materiais e culturais.

\section{Socialização para a vida adulta através da cultura material}

Em 2008, a organização norte-americana

\section{California Milk Processor Board (CMPB)}

realizou uma pesquisa cujo objetivo era investigar os motivos que levavam ao declínio do consumo de leite, principalmente entre os adolescentes. 0s resultados indicaram que este público não achava que beber leite era cool (gíria em inglês que indica, em Português, algo como "legal"):

Os resultados da pesquisa mostraram que os consumidores cada vez mais bebiam menos leite na medida que envelheciam e que 0 abandono do hábito de beber leite começava em torno da idade de 10 anos. Conforme os jovens consumidores progrediam através de sua adolescência, 0 consumo de leite diminuía consideravelmente enquanto 0 consumo de outras bebidas aumentava na mesma medida. Consumidores entre 18 e 24 anos bebiam 166 litros de bebidas leves, mas bebiam apenas 65 litros de leite ${ }^{12}$.

12 Tradução livre do original: "Research data showed that consumers steadily drank less milk as they aged and that their shift away from drinking milk began around the age of 10 . As young consumers progressed through their teen years, their milk consumption steadily declined while their consumption of other beverages steadily increased. Consumers between 18 and 24 drank 44 gallons of soft drinks, but they drank only 17.2 gallons of milk." Disponível em http://www.aef.com/on_ campus/classroom/case_histories/3000. Acessado em 17 de junho de 2016. 
Em matéria publicada na revista Veja, na edição de 20 de novembro de 1991, "tribos" de jovens da periferia de São Paulo são apresentados a partir de seus padrões subculturais e, em alguns casos, violentos. 0 depoimento de um dos entrevistados ganha destaque: "Gostamos de bater nos góticos, rockabillies e homossexuais. E também nos skinheads, todos boyzinhos que tomam Toddy de manhã" (Lima, 1991, p. 68).

A relação entre 0 baixo consumo de leite e a adolescência, e entre o Toddy e os "boyzinhos", ou quaisquer outras do gênero, não pode ser explicada a partir de aspectos racionais ou utilitaristas. Trata-se, como procura-se aqui demonstrar, de uma construção social que ordena o mundo material e o mundo cultural através de signos, categorias e representações.

Como já demonstrou o trabalho de Dant (2006), há uma estreita relação entre cultura material e civilização. Observar de que modo a materialidade interage com os indivíduos de uma sociedade em um dado percurso histórico revela que a humanidade civiliza-se na medida que aprimora o seu relacionamento com as coisas. Da mesma forma, pensando em menor escala, pode-se afirmar que o percurso da vida biológica nos coloca em constante interação com as coisas materiais, que nos conduzem para um processo de socialização para substituir a contento o termo civilização.

0 Quadro 2 demonstra que o leite é um alimento diretamente relacionado - por construção social, resultado da experiência da vida prática, evidentemente - com a maternidade. Desta relação fortemente impregnada de natureza, desdobram-se outras, como com o feminino, a família, a emoção e a criança. A passagem das fases da vida é marcada por alguns ritos, a partir dos quais vai-se de um estágio para o outro. Alguns desses ritos de passagem são vivenciados coletivamente e bastante demarcados, como 0 Bar Mitzvah ou a Festa de 15 anos, por exemplo. Outros, porém, são invisibilizados pela rotina. A mudança de hábitos alimentares é também um marcador social destas passagens da fase da vida. Do seio para a mamadeira de leite, acrescentamse maçãs raspadas e papinhas, depois sopas sólidas, depois comidas mais consistentes. Mais tarde, quando a criança entra para a escola, os refrigerantes, balas e doces são inescapáveis. 0 primeiro prato de salada, o primeiro pedaço de pizza, o primeiro tablete de chocolate... difícil esquecer essas experiências. Mas não são ritos, são práticas rotineiras. Trata-se de um relacionamento entre indivíduo e comida que 0 conduz para a infância, a adolescência, a vida adulta e 0 envelhecimento.

Estas premissas explicariam, portanto, o motivo por que os adolescentes norte-americanos rejeitam o leite quando chegam aos 10 anos: eles não querem mais ser crianças e passam a evitar coisas materiais que fazem parte do mundo infantil, como bonecos, determinados tipos de roupas e leite. Passam, então, para novos tipos de bebidas. Normalmente, há 0 
momento em que os pais deixam a criança experimentar o café-com-leite. Quando não se adaptam ao novo sabor, tenta-se 0 achocolatado. Na adolescência tardia, permite-se que tomem café. Neste momento, novas categorias já estão incorporadas àquele momento de vida, como 0 gosto por sabores mais encorpados (quase amargos, antes intragáveis a paladares infantis), bebidas muito quentes, xícara ao invés de copos, decisões mais racionais do que levadas pela emoção.

Este artigo está longe de afirmar que adultos não bebem leite nem achocolatados - é claro que sim, mas provavelmente em momentos em família, aconchegantes, divertidos, e raramente pública e socialmente. Porém, as relações com tais alimentos mudam em função de sua fase de vida.

0 leite, portanto, mostra-se aqui como um demarcador importante - e significante - nesta transição da criança para 0 adulto, da natureza para a vida em sociedade. Quanto mais próximo do leite, mais próximo da infância. Quanto mais longe do leite, mais próximo da vida adulta.

A publicidade, por fim, é um facilitador deste processo de socialização, ensinando-nos e lembrando-nos de que determinadas coisas pertencem a determinados mundos, sendo necessário que nos associemos a esta ordem para que também estejamos dentro de uma ordem maior, adequada aos olhos do Outro, familiar para os padrões coletivos e socialmente aceita.

\section{Considerações finais}

0 objetivo deste artigo foi discutir o lugar da publicidade no processo de construção das representações midiáticas do café e do chocolate, de acordo com uma dada classificação simbólica. A discussão girou em torno da cultura material como parte da dinâmica da cultura humana, em todos os níveis.

Foram analisados doze anúncios impressos, sendo sete de chocolate e cinco de café. A partir daí, elaboraram-se esquemas baseados na vertente estruturalista da antropologia, com inspiração na obra Cultura e Razão Prática, de Marshall Sahlins (2003). Além dele, importantes autores que realizam a interlocução entre antropologia, comunicação e cultura material serviram de base para as reflexões aqui apresentadas, com destaque para Daniel Miller.

Concluiu-se que as categorias materiais do café e do chocolate correlacionam-se com categorias culturais que nos levam a observar, entre outras coisas, que há um processo de socialização durante a fase da vida, na qual o leite é um demarcador fundamental na mudança de hábitos alimentares, do achocolatado para o café.

Fica em aberto qualquer afirmação mais conclusiva sobre a objetificação, no sentido dado por Miller, do café e do chocolate. Para tanto, seria necessário um trabalho de campo para uma etnografia, o que não é objetivo deste 
trabalho. Arrisca-se conjecturar, porém, que há, na dinâmica relacional chocolate/café e criança/ adulto, intermediada pela presença/ausência do leite, uma objetivação da autonomia. Uma autonomia buscada por aqueles que se encontram diante dos desafios da transição que levam para a adolescência e, depois, para a vida adulta. Mas, como disse, trata-se apenas de uma suposição, inspiração para futuros trabalhos.

\section{Referências}

APPADURAI, Arjun. Introdução: Mercadorias e a política do valor. In: APPADURAI, Arjun. A vida social das coisas. Niterói: Editora da Universidade Federal Fluminense, 2010.

A vida social das coisas.

Niterói: Editora da Universidade Federal Fluminense, 2010.

BOURDIEU, Pierre. A distinção: crítica social do julgamento. São Paulo: Edusp, Porto Alegre: Zouk, 2008.

DANT, Tim. Materiality and society. British

Journal of Sociology, Vol. 57 (2): 289-308, June 2006. Disponível em http://core.ac.uk/download/pdf/71307. pdf. Acessado em 17 de junho de 2016.

DOUGLAS, Mary; DOUGLAS, Isherwood. 0 mundo dos bens: para uma antropologia do consumo. Rio de Janeiro: Editora UFRJ, 2004.

GEERTZ, Clifford. A interpretação das culturas. Rio de Janeiro: LTC, 1989.

HALL, Stuart. The work of representation. In: HALL, Stuart (org.). Representation, cultural representation signifying practices. London/ Thousand 0aks/New Delhi: Sage/Open University, 1997. HOGGART, Richard. As utilizações da cultura: aspectos da vida da classe trabalhadora, com especiais referências a publicações e divertimentos. Lisboa: Editorial Presença, 1973. KOPYTOFF, Igor. A biografia cultural das coisas: a mercantilização como processo. In: APPADURAI, Arjun. A vida social das coisas. Niterói: Editora da Universidade Federal Fluminense, 2010.

LÉVI-STRAUSS, Claude. Totemismo hoje. In: A noção de estrutura e etnologia; Raça e História; Totemismo hoje. São Paulo: Abril Cultural, 1980. 0 pensamento selvagem.

Campinas: Editora Papirus, 1989.

LIMA, João Gabriel de. 0 uivo da periferia. Revista Veja, 20 de novembro de 1991.

MAUSS, Marcel. Ensaio sobre a dádiva. In: MAUSS, Marcel. Sociologia e antropologia. São Paulo: Cosac \& Naify, 2003.

\section{MILLER, Daniel. Material Culture and Mass}

Consumption. New York: Basil Blackwell Inc., 1987.

Disponível em http://townsendgroups.berkeley.edu/sites/ default/files/miller_-_material_culture_and_mass consumption.pdf. Acessado em 17 de junho de 2016. . Artefacts and the meaning of things. In T. Ingold (ed.), Companion Encyclopedia of Anthropology, London: Routledge, 1994.

Teoria das compras. São Paulo:

Nobel, 2002.

Tales from Facebook. Cambridge:

Polity Press, 2011.

The unpredictable mobile phone.

In: BT Technology Journal • Vol 24 No 3 • July 2006. Disponível em http://research.microsoft.com/en-us/ um/people/cutrell/papers/miller-unpredictable\%20 mobile\%20phone.pdf. Acessado em 17 de junho de 2016. MILLER, Daniel; WOODWARD, Sophie. Blue Jeans: the art of the ordinary. Berkeley and Los Angeles: 
University of California Press, 2012. Acessado em 17 de junho de 2016.

MOSCOVICI, Serge. Representações sociais:

investigações em psicologia social. Petrópolis: Ed.

Vozes, 2011.

ROCHA, Everardo. Magia e capitalismo: um estudo antropológico da publicidade. São Paulo: Ed.

Brasiliense, 2010.

SAHLINS, Marshall. Cultura e razão prática. Rio de Janeiro: Jorge Zahar, 2003.

WILLIAMS, Raymond. Cultura e Sociedade: de

Coleridge a Orwell. Petrópolis: Vozes, 2011.

WOODWARD, Kathryn. Identidade e diferença: uma introdução teórica e conceitual. In: SILVA, Tomaz Tadeu da (org.). Identidade e diferença: a perspectiva dos

Estudos Culturais. Petrópolis: Vozes, 2000. 


\section{Awakening for material culture: media representations of coffee and chocolate in advertising}

\section{Abstract}

The aim of the article is to discuss, in light of

anthropological theories, especially those addressed to consumption analysis and to material culture as social phenomenon, the representations of some "things" in their relationships to values and practices of western contemporary culture - in this case, coffee and chocolate, in their media representations in Advertising. Therefore, this work is based on authors as Marshall Sahlins (2003) and Daniel Miller (1987), among others. From what was here analyzed assumptions are reinforced that "things" and "people" constitute parts of the same cultural ontology linked by logics which are beyond practical reason.

\section{Keywords}

Material culture. Media representations. Advertising.

\section{Despertar a la cultura material: representaciones del café y del chocolat en la publicidad}

\section{Resumen}

El objetivo de este artículo es discutir, a la luz de las teorías antropológicas, especialmente los que se dedican al análisis del consumo y la cultura material como fenómenos sociales, representaciones de ciertas "cosas" en sus relaciones con los valores y prácticas de la cultura occidental contemporánea aquí, el café y chocolate en sus representaciones de los medios de publicidad. Por lo tanto, este trabajo se sostiene en autores como Marshall Sahlins (2003) y Daniel Miller (1987), entre otros. De lo que se ha discutido aquí, los supuestos que refuerzan "cosas" y "personas" son parte de la misma ontología culturales, unidos por lógicas que están más allá de la razón práctica.

\section{Palabras clave}

Cultura material. Representaciones. Publicidad. 


\section{Expediente}

A revista E-Compós é a publicação científica em formato eletrônico da Associação Nacional dos Programas de Pós-Graduação em Comunicação (Compós). Lançada em 2004, tem como principal finalidade difundir a produção acadêmica de pesquisadores da área de Comunicação, inseridos em instituições do Brasil e do exterior.

\section{E-COMPÓS I www.e-compos.org.br I E-ISSN 1808-2599}

Revista da Associação Nacional dos Programas de Pós-Graduação em Comunicação.

Brasília, v.20, n.1, jan./abr. 2017.

A identificação das edições, a partir de 2008, passa a ser volume anual com três números.

Indexada por Latindex I www.latindex.unam.mx

\section{CONSELHO EDITORIAL}

Alda Cristina Silva da Costa, Universidade Federal do Pará, Brasil Alfredo Luiz Paes de Oliveira Suppia, Universidade Estadual de Campinas, Brasil Álvaro Larangeira, Universidade Tuiuti do Paraná, Brasil Ana Carolina D. Escosteguy, Pontifícia Universidade Católica do Rio Grande do Sul, Brasil Ana Regina Barros Rego Leal, Universidade Federal do Piauí, Brasil Ana Carolina Rocha Pessôa Temer, Universidade Federal de Goiás, Brasil Andrea França, Pontifícia Universidade Católica do Rio de Janeiro, Brasil André Luiz Martins Lemos, Universidade Federal da Bahia, Brasil Angela Cristina Salgueiro Marques, Faculdade Cásper Libero, Brasil Ângela Freire Prysthon, Universidade Federal de Pernambuco, Brasil Antonio Carlos Hohlfeldt, Pontifícia Universidade Católica do Rio Grande do Sul, Brasil Arthur Ituassu, Pontifícia Universidade Católica do Rio de Janeiro, Brasil Bruno Campanella, Universidade Federal Fluminense, Brasil Cláudio Novaes Pinto Coelho, Faculdade Cásper Líbero, Brasil Carlos Eduardo Franciscato, Universidade Federal de Sergipe, Brasil Denise Tavares da Silva, Universidade Federal Fluminense, Brasil Eduardo Vicente, Universidade de São Paulo, Brasil Eliza Bachega Casadei, Escola Superior de Propaganda e Marketing - SP, Brasil Elizabeth Nicolau Saad Corrêa, Universidade de São Paulo, Brasil Erick Felinto de Oliveira, Universidade do Estado do Rio de Janeiro, Brasil Erly Vieira Júnior, Universidade Federal do Espirito Santo, Brasil Francisco de Assis, FIAM-FAAM Centro Universitário, Brasil Francisco Elinaldo Teixeira, Universidade Estadual de Campinas, Brasil Frederico de Mello Brandão Tavares, Universidade Federal de Ouro Preto, Brasil Gabriela Reinaldo, Universidade Federal do Ceará, Brasil Gilson Vieira Monteiro, Universidade Federal do Amazonas, Brasil Gustavo Daudt Fischer, Universidade do Vale do Rio dos Sinos, Brasil Igor Sacramento, Fundação Oswaldo Cruz, Brasil Itania Maria Mota Gomes, Universidade Federal da Bahia, Brasil Jiani Adriana Bonin, Universidade do Vale do Rio dos Sinos, Brasil José Afonso da Silva Junior, Universidade Federal de Pernambuco, Brasil
José Luiz Aidar Prado, Pontifícia Universidade Católica de São Paulo, Brasil Juçara Gorski Brittes, Universidade Federal de Ouro Preto, Brasil Laura Loguercio Cánepa, Universidade Anhembi Morumbi, Brasil Liziane Soares Guazina, Universidade de Brasilia, Brasil Luíza Mônica Assis da Silva, Universidade Católica de Brasília, Brasil Maria Ataide Malcher, Universidade Federal do Pará, Brasil Maria Elisabete Antonioli, Escola Superior de Propaganda e Marketing - SP, Brasil Maria das Graças Pinto Coelho, Universidade Federal do Rio Grande do Norte, Brasil Marcel Vieira Barreto Silva, Universidade Federal da Paraíba, Brasil Marcia Tondato, Escola Superior de Propaganda e Marketing, Brasil Marli Santos, Universidade Metodista de São Paulo, Brasil Márcio Souza Gonçalves, Universidade do Estado do Rio de Janeiro, Brasil Mauricio Mario Monteiro, Universidade Anhembi Morumbi, Brasil Mauricio Ribeiro da Silva, Universidade Paulista, Brasil Mauro de Souza Ventura, Universidade Estadual Paulista, Brasil Mayka Castellano, Universidade Federal Fluminense, Brasil Micael Maiolino Herschmann, Universidade Federal do Rio de Janeiro, Brasil Mozahir Salomão Bruck, Pontifícia Universidade Católica de Minas Gerais, Brasil Nísia Martins Rosario, Universidade Federal do Rio Grande do Sul, Brasil Potiguara Mendes Silveira Jr, Universidade Federal de Juiz de Fora, Brasil Raquel Ritter Longhi, Universidade Federal de Santa Catarina, Brasil Regiane Regina Ribeiro, Universidade Federal do Paraná, Brasil Roberto Elísio dos Santos, Universidade Municipal de São Caetano do Sul, Brasil Rodolfo Rorato Londero, Universidade Estadual de Londrina, Brasil Sérgio Luiz Gadini, Universidade Estadual de Ponta Grossa, Brasil Simone Maria Andrade Pereira de Sá, Universidade Federal Fluminense, Brasil Simone Maria Rocha, Universidade Federal de Minas Gerais, Brasil Suzana Reck Miranda, Universidade Federal de São Carlos, Brasil Tarcyanie Cajueiro Santos, Universidade de Sorocaba, Brasil Tatiana Oliveira Siciliano, Pontifícia Universidade Católica do Rio de Janeiro, Brasil Veneza Mayora Ronsini, Universidade Federal de Santa Maria, Brasil

\section{CONSELHO CIENTÍFICO}

Cristiane Freitas Gutfreind, Pontifícia Universidade Católica do Rio Grande do Sul, Brasil Eduardo Morettin, Universidade de São Paulo, Brasil

Felipe Costa Trotta, Universidade Federal Fluminense, Brasil Irene de Araújo Machado, Universidade de São Paulo, Brasil

\section{COMISSÃO EDITORIAL}

Eduardo Antonio de Jesus, Universidade Federal de Minas Gerais, Brasil Marco Antonio Roxo da Silva, Universidade Federal Fluminense, Brasil Osmar Gonçalves dos Reis Filho, Universidade Federal do Ceará, Brasil

\section{CONSULTORES AD HOC}

Kelly C. de Souza Prudencio, Universidade Federal do Paraná, Brasil Francisco P. Jamil A. Marques, Universidade Federal do Paraná, Brasil Tiago Quiroga F. Neto, Universidade de Brasília, Brasil

\section{EQUIPE TÉCNICA}

ASSISTENTE EDITORIAL Márcio Zanetti Negrini REVISÃO DE TEXTOS Press Revisão EDITORAÇÃO ELETRÔNICA Roka Estúdio IMAGEM DE CAPA Silas de Paula

\section{COMPÓS I www.compos.org.br}

Associação Nacional dos Programas de Pós-Graduação em Comunicação

Presidente

Edson Fernando Dalmonte

Programa de Pós-Graduação em Comunicação

e Cultura Contemporânea - UFBA

edsondalmonte@uol.com.br

Vice-presidente

Cristiane Freitas Gutfreind

Programa de Pós-Graduação em Comunicação Social - PUC-RS cristianefreitas@pucrs.br

Secretário-Geral

Rogério Ferraraz

Programa de Pós-Graduação em Comunicação

Universidade Anhembi Morumbi

rogerioferraraz@anhembimorumbi.edu.br

CONTATO I revistaecompos@gmail.com 